Florina ILIS

Faculty of Letters, Babeş-Bolyai University

Cluj-Napoca, Romania

ilisflorina@gmail.com

\title{
THE EMERGENCE OF VIOLENCE AND THE TERROR OF BEING BORN IN MURAKAMI'S COIN LOCKER BABIES
}

Recommended Citation: Ilis, Florina. "The Emergence of Violence and the Terror of Being Born in Murakami's Coin Locker Babies." Metacritic Journal for Comparative Studies and Theory 7.1 (2021):

https://doi.org/10.24193/mjcst.2021.11.16

\begin{abstract}
Modern poetics imposed the image of Nietzsche's split Subject, with the disaggregated self-emerging as dilemmatic subjectivity and its aesthetic culmination in the "dehumanisation of art." Nietzsche's philosophy provided postmodern poetics with the Subject as "fiction," subjected to a complex process of self-multiplication and self-reflection (Ihab Hassan). The loss of the autonomy of the Subject as a "fashionable theme" (Frederic Jameson), combined with its multiplication into simulacra (Jean Baudrillard) and the abolition of reference, allow the Object to storm the places of its absence. The multiplicitous nature under which the image of subjectivity is formed is a possible solution for the issue of the Subject. Another solution would be inflicting violence upon the Subject, replaced by the corporeality of the Object, by the body, to the point of its destruction, or to the ultimate point of abjectness. My essay will use Murakami Ryū's novel Coin Locker Babies to examine its author's views on the ObjectSubject relation, on the Subject as an Object (corporeality) and on the forms through which the Object inflicts violence upon the Subject.
\end{abstract}

Keywords: Object, Subject, Violence, Material imagination (busshitsuteki), Animality (dōbutsusei)

From his very debut in 1976, with the novel Almost Transparent Blue (Kagirinaku Tōmeini Chikai Burū限りなく透明に近いブルー), Ryū Murakami surprised both critics and readers with the direct and free manner in which he approached sexuality and its excesses. For this novel, the writer received the Akutagawa award, and the 
success of the book was reflected by the approximately 1.400.00o copies sold by the end of 1976. Born on February $18^{\text {th }} 1952$, in Sasebo, Ryū Murakami was part of a generation of writers who had grown up watching American western movies, passionately reading science fiction, as well as listening to jazz music and keeping up with comic book heroes. Influenced by the American pop culture, Ryū Murakami also became interested in rock music and he formed a band for which he composed songs. His passion for rock and for the lives of the stars was later (1980) expressed in the novel Coin Locker Babies (コインロッカー・ベイビーズ, Koinrokkābeibīzu). One of the protagonists of the book, Hashi, became a rock star, fascinated by music's power to dominate and seduce the crowds through his voice, following the model of the American rock stars. Moreover, the subject of sexual violence, of orgies and of the desire to surpass all of the body's limitations or even the borders of sexuality, a main theme of his debut novel Almost Transparent Blue, can be found in his later novel, Coin Locker Babies, but in a manner that was more sophisticated than the transparent style by which the subject had been approached in his first novel.

From Almost Transparent Blue, to Old Terrorist (Ōrudo Terorisuto オールド テロリスト), from 2015, Ryū Murakami's novels aimed to represent the new - and uncosmeticized - expression of a Japan that was deeply influenced by the American pop culture. His characters, although they lack heroism, at least maintain the illusion that, at the end of an adventure reduced to a series of acts of violence going past the limits of endurance, they would find something absolute and pure, a world with no past or memory, a fluid world. In a universe where good and evil are difficult to distinguish, since excess has become the norm, and the laws of consumption dictate upon emotions and create sentiments that disappear just as quickly after the fulfilment of the desire for possession on which they had been based, Ryū Murakami's novels do not shy away from directly approaching all of the taboos represented by themes such as drugs, alcoholism, prostitution, sadomasochism and sexual perversions. The author's nonconformism and his desire to attack all of the traditional Japanese social values are also expressed in his non-fictional texts, which bear titles that, by contrast, offer an inversed, ironic view on Japan and, implicitly, on the world: SEX is better than Suicide: Ryū Murakami's theory of love and woman (Jisatsuyoriwa SEX Murakami Ryū no Renai Jōseiron 自殺よりはSEX 村上龍の恋愛 · 女性論, 2003) or Unexpectedly, I’m a shopping lover (Angai, kaimono suki 案外、買い物好き, 2007) 
and Encouragement of having no hobby (Mushumi no susume 無趣味のすすめ, 2009).

When the subject of violence exhausts its resources, Ryū Murakami explores the subject of possible or alternative universes, an idea borrowed from science fiction; however, unlike his contemporary, Haruki Murakami, in whose novels possible worlds play a central role in counteracting the platitude of reality (Frențiu 135-50), Ryū Murakami has a more provocative perspective on the subject. By skillfully juggling with certain elements of the science fiction imagination, Ryū Murakami adapted the theme of possible worlds to his subject of interest, and not vice versa. Thus, while the plot of Coin Locker Babies progresses towards an apocalyptic ending, seen as a consequence of the existence of an alternative world, seemingly subdued by the more realistic nature of representation, the theme of parallel worlds or of counterfactual history has been gaining primacy. An example is the novel From the Fatherland, with Love (Hantōo Deyo半島を出よ) (2015), which constructs a dystopian world in which North Korea invades and occupies Japan.

Brian McHale explains the role played by science fiction in galvanizing postmodern literature. He describes the migration of certain themes from the science fiction imagination as a double-edged process, showing that novels borrowed themes that had previously been postmodernized by science fiction, absorbing them only after they had been contaminated by pop culture: “(...) we find postmodernist texts absorbing materials from SF texts that have already been 'postmodernized' to some degree through contact with mainstream postmodernist poetics" (McHale 228-9). Thus, themes typically assigned to science fiction (such as counterfactual history, parallel universes or possible worlds) became current in the works of authors such as Thomas Pynchon, in Gravity's Rainbow, or Christine Brooke-Rose, in Verbivore and in Xorandor, as well as Umberto Eco, in Foucault's Pendulum. In the case of the Japanese writers Ryū Murakami and Haruki Murakami, their contact with pop culture and with postmodern fiction took place almost simultaneously. This is why their approaches to parallel universes and possible worlds rely especially on the ontological dimension of the world-creating text, which diminishes their subversive or political effects. Without undermining or questioning the text's ability to create new worlds, such themes provide Ryū Murakami's writing with an ethical dimension, but one devoid of the certainty of a moral; in Haruki Murakami's case, they produce an 
ontological dimension, but one often located in the vicinity of the miraculous, like in the novel Hard-Boiled Wonderland and the End of the World (Sekai no owari to Hādo-boirudoＷandārando世界の終りとハードボイルドワンダーランド), published in 1985 .

Thus, by experimenting with the ontological capacity of the text to create worlds while eschewing science fiction's founding convention (that of future worlds), the two Japanese authors rely on ontological innovation. Stimulating the ability of the text to produce worlds, they avoid any metaphysical and/or moral charge. The "aesthetization" of the shock produced by the post-industrial society resulted, in Ryū Murakami's case, in a form of fiction which demystifies the conventions behind the creation of a possible world. This significant ambiguity of constructing and deconstructing meaning also motivates the author's interest in the theme of parallel universes and its variations.

Coin Locker Babies is not an avant-la-lettre science fiction novel, since the main plot takes place in today's Tokyo, where two areas can be outlined - the real one, represented by the Shinjuku district, with the thirteen skyscrapers, and the imaginary one, Toxitown, which seems to have sprung from the post-atomic imaginary. The plot adapts the common science fiction convention of the world under attack to a rather traditional narrative formula. Ostensibly constructed as a Bildungsroman, Ryū Murakami's story follows the lives of two children who have survived the trauma of having been abandoned a few hours after birth in coin-operated-lockers in the train station. Despite the story having been borrowed from a real-life news report, the plot gradually and almost imperceptibly abandons the traditional realist structure; however, the transition to the alternative universe is not as visibly marked as in Haruki Murakami's novels. The novel is inspired by mediatic accounts of children abandoned in the coin lockers. According to statistics, 191 cases of children who had died suffocated in coin lockers were reported between 1980-1990 (Kouno, Johnson 25-31).

Given the authenticity of the novel's inspiration and the two abandoned children at the center of the story, Murakami Ryū could have opted for classical pattern of the Bildungsroman. He only does so in part, and solely in order to gradually blur the realist dimension. Through the subtlety by which he conceives the alternative of a possible universe, dominated by the madness of the two main characters, he manages to convince the reader of the necessity of destroying a world which steals the people's 
freedom, limiting any possibility of movement. In the eyes of others, Hashi and Kiku are insane, but, in their own view, the entire world is insane, dominated by a madness that is ignored and, as such, must be challenged. Both Hashi, through his songs, and Kiku, through the destruction he was planning, also play the roles of agitators, of challengers of an immobile world that lacks a soul and, implicitly, that lacks history and memory.

The two main characters, Hashi and Kiku, are both animated by the spirit of negation, as a form of the absolute freedom of an individual that refuses to accept any type of order, be it ethical or transcendental. However, their behaviours differ, since each have their own relationship with the traumatizing memory of being abandoned by the mothers who had given them life.

After being found in the coin lockers, the two children are placed in the care of nuns in the Cherryfield Orphanagem who raise them until, one year before starting school, they are adopted by a family living on an isolated island west of the Kyūshū province. When Hashi runs away from home, Kiku and Kazuyo, their adoptive mother, leave for Tokyo in search for him. After Kazuyo's strange death, Kiku decides to stay in Tokyo in order to reach Toxitown, where Hashi lived. He accidentally meets Anemone, whom he tells about a chance of obtaining a scathing gas that would destroy the city. From this point on, the twins' existences are separated, despite the fact that they both pursue the same final goal: the destruction of the world, albeit through different means. Thus, while Hashi desires the destruction of the world and of the traumatizing memory of birth and the annihilation of time - symbolically represented by murdering the foetus in the mother's womb, Kiku desires destruction through violence inflicted on the spatial world order - an order symbolically represented by the city Centre and by the thirteen skyscrapers. The world order, conceived mechanistically, as an enormous structure of coin lockers, must be destroyed, so that the ones trapped inside the lockers could be liberated and could thus live freely.

The metaphor of the world as an enormous coin locker is built gradually, as the two children grow older and, after leaving the small island where they had been adopted, they come to understand that the tragedy of being abandoned at birth is part of the human condition. However, Ryū Murakami avoids this direction and does not build an existentialist tragedy, which would actually have no effect in a post-industrial society fuelled by consumption and pleasure, where the message of Christian metaphysics is almost non-existent. This aspect is, in fact, also suggested by the author 
through the fact that, despite having been raised in the Cherryfield Orphanage, the two children had not been touched by the Christian message. Stephen Snyder does not base his reading of the novel on the religious connotation of the idea of good/evil either. Instead, he interprets it through a postmodernist lens, following Jean Baudrillard, as "a vital principle of disjunction." According to Snyder, Ryū Murakami pushed the manifestation of Evil to its final consequences, and the effect of this acceleration leads to destabilizing the stable (Snyder 211) in contemporary society. In other words, precisely the goal pursued by the two characters, Kiku and Hashi. Both in the case of Kiku and in that of Hashi, Evil represents the ultimate violence, namely attempted homicide and murder.

By remoulding the science fiction convention of possible universes in accordance with contemporary taste, in Ryū Murakami's novel, Kiku's act of destroying the city of Tokyo loses its heroic meaning. The goal of seeking the center on which every heroic adventure is based is converted into the obsession for destroying the center and, implicitly, destroying the order it represents, not by virtue of rebuilding, but from the desire to replace it with its opposite - with the lack of order, with chaos. The final scene of the novel, in which Hashi crosses the deserted city center that had been devastated by the toxic gas released by Kiku is thus quite revealing.

However, in a universe sentenced to destruction, in the science fiction literature, heroes always emerge, namely heroes in the service of man, who attempt to save the world; in the universe conceived by Ryū Murakami, for the two protagonists - the children who had been abandoned by their mothers in coin lockers - the only possible adventure remains the desire to kill the only memory of the mother, namely the sound of her heartbeat, heard as foetuses and kept on the level of the subconscious. Thus, Hashi desperately seeks this sound through music and, when this fails, he tries, in an extreme attempt to exorcise Evil, to murder his own child, by attacking his pregnant wife. After this attack, Hashi is admitted to a psychiatric clinic. Kiku, after a series of adventures, manages to obtain the mysterious Datura gas, which was known to cause massive destruction in the city. What is interesting in his case is that, after murdering the biological mother and after his sentencing to prison, his desire for destruction seems to have decreased in intensity. However, his insanity is transferred to Anemone, who receives the role of an agent of remembrance. She reminds Kiku that, in a universe dominated by the laws of consumption, the idea that life's sacred values remain intact is an illusion, and that individual salvation is impossible, since true 
salvation can take place only when the world order is destroyed, in favour of a new order. It is unclear whether the order envisioned by Anemone is the one from the Kingdom of Crocodiles, and what exactly that would imply.

Hashi and Kiku's reaction against the world, beyond the psychological explanation offering it as a normal reaction for children abandoned at birth in coin lockers, is also a response to terrible social aggression; it represents the impulse to oppose a world that reduces the individual to the state of an object, nameless and standardized in the form of a coin locker, by replacing it with a universe uninhabited by people, upon which nature rules, as in the former mining town on the island.

In the final scene of the novel, Hashi is once again dominated, because of the desire to save himself, by an evil force that orders him to kill the unborn child of a pregnant woman encountered on the deserted streets of the devastated city. Starting this image and from the concept defined by Julia Kristeva as "ultimate abjection," Stephen Snyder considers that the attempted murder of the pregnant woman represents "the violation of the most inviolable of images, the pregnant female body" (Snyder 212). In Snyder's interpretation, the ending, despite the devastation of the city, is almost optimistic. The effect of the violence inflicted upon the pregnant woman is that of a true act of exorcism, since, by attacking her, Hashi regains access to his biological memory and, realizing this, he understands that the sounds he so desperately sought through music were actually his mother's heartbeats, which he had heard as a fetus. By reliving and consciously remembering the aggression of his own birth - any birth implies an act of violence by expelling the fetus out of the protective space of the womb - and, by exorcising his own violence, thus freeing himself from under the rule of evil, Hashi tries to surpass the vision of the coin locker that had compelled him to lead a life dominated by violent autistic episodes.

By coming to terms with the memory of the woman who had given him life and then abandoned him, Hashi also gained his free will, becoming able to fight the desire to murder the pregnant woman encountered on the deserted streets of the contaminated city. The desire to compose a new song helps him liberate himself from the oppressive forces of his inner life and to reconnect with the outside world through the music that had always helped him break away from his memories, through an almost cathartic or even confabulatory process: "Hashi himself was surprised how easily he was able to manipulate the self inside his head, even down to his memories, to make it resemble the confident person he projected on TV" (Murakami 224-5). 
Confabulation is a technical term that describes the situation of the patients "who have problems with their memory or their self awareness" (Bryson 334).

The world envisioned by Ryū Murakami, constructed as an enormous coin locker, excludes individual freedom. As such, the individual, reduced to a mere object abandoned in these lockers, seems to transform from a human being with normal reactions into one with reflex responses to the violence inflicted upon him by the world that sees him as an object. The violence of language, the violence of actions, the violence elevated to an absolute level of value, in the author' view, represent the only means of restoring some of the world's meaning, which had been lost through the levelling, trivialising process promoted by the consumer society. The scenes of violence accelerate towards the end, leading Hashi to an insane asylum and Kiku to the release of the gas upon the city of Tokyo; the scenes follow one another with such speed and with such a blatant disregard for any moral censorship, that, through the effects of exaggeration and overemphasis, they tend to encroach upon the entire tableau. Violence is the only thing that can still move world exclusively dominated by the power of money and of promoting false images, a world where reality has been replaced by the simulacrum, as shown by the French sociologist Jean Baudrillard. Considering the evolution of postmodern society, Jean Baudrillard outlines, from a sociological perspective, a new view on confronting the individual with reality and with the order affected by the lack of a temporal dimension, rooted in the present. Within this "desert" of reality, the theory of the simulacra and simulations gains consistency. In Jean Baudrillard's view, we are traversing a world of simulacra, for which reality, more and more determined by the intensification of models, changed its initial meaning, disappearing under a network of miniature units and databanks (Baudrillard 167) that forever multiply, in order to bring forth the images that would form the hyper-real. It is "the age of simulation," which begins with "a liquidation of all referentials" (Baudrillard 167). The transition from the real to the hyper-real occurs when representation is replaced by simulation. This loss of reality in favour of an increase in simulacrum is due to the increasingly more complex control held by the means of information and communication within the consumer society. According to Baudrillard, it is more "a question of substituting signs of the real for the real itself" (167), which leads to a new way of understanding the world, an understanding that is no longer direct, referential, but mediated and conditioned by the signs of the real, and not by the real itself. Jean Baudrillard notes that the simulacrum of the real 
occurred in successive phases, as the strategies of the media technologies perfected their abilities to erode reality, in four successive phases of erecting the edifice of representation. Thus, in the first phase, reality is reflected by the sign ("It is the reflection of a basic reality"), in the second phase the sign "masks and perverts a basic reality," and in the third phase "it masks the absence of a basic reality," so that in the final phase, the sign no longer has anything to do with reality ("It bears no relation to any reality whatsoever: it is its own pure simulacrum") (Baudrillard 170).

To the same extent, the individual is no longer confronted by reality directly, but with its perfect simulacrum, which replaced it - the hyper-real. A dive into the hyper-real can take place concomitantly with the "liquidation" of all systems of reference, and the level of significance that separates the real form the imaginary is thus destroyed as a result of this process: "A hyperreal henceforth sheltered from the imaginary, and from any distinction between the real and the imaginary, leaving room only for the orbital recurrence of models and the simulated generation of difference" (Baudrillard 170).

Postmodern theory and practice suggest that knowledge has always been mediated by representations. Thus, the re-invention of the real in the form of fiction is more than just an option for literature, it is a condition. The order of the imaginary is reversed - the unreal ca no longer be built from the data provided by the real, but, with the already existing models of the simulation, the real should be rebuilt. In the case of Ryu Murakami's text, such a model is represented by the post-apocalyptic image of the world, an image borrowed from classical science fiction literature, readdressed and re-signified in a postmodern manner. Postapocalyptic imagery becomes integrated and reinterpreted by postmodernism; however, in Coin Locker Babies, it also plays the role of a simulacrum in the sense defined by Baudrillard, since fiction and real events overlap, abolishing the distance between the imaginary and the real. It comes therefore as no surprise that Coin Locker Babies came to be seen as foreshadowing the sarin gas attack on the Tokyo subway, and Ryū Murakami was often regarded as a visionary writer.

The post-apocalyptic ending, dominated by Hashi's song, suggesting that salvation may come through an art form, reveals the second level of the text which, without disbanding the primary level of the plot, foregrounds its hallucinatory nature. In this sense, the attack on the world order is doubled, on a fictional level, by an impairment on the norms of fiction, through a technique that is rather characteristic 
to the visual arts, which can overlap distinctive spaces through ingenious optical effects. In an apparently simple composition, with the plot following two primary levels in relation with the evolution of the lives of the two children, the novel abandons conventions. Through the multiplication of scences of violence, to the brink of the unbearable, a strange effect is obtained, namely that of a well-tempered surrealism produced by the excess of certain violent scenes that dominate the background, in relation with the foreground. Therefore, a second, unreal, distant level of the plot is created. The technique of oversizing the effect of violence on the secondary level plays the role of concomitantly annihilating and accentuating the distance between the reality of the text and the super-reality thus built. One scene associated with this technique is the one from the end of the novel, in which Hashi attacks the pregnant woman, while Kiku releases the baneful gas upon the city. Thus, at the end of the novel, the more distant level - oversizing the power of the two protagonists - imposes itself with so much force, that it comes to annihilate the fictional ontology, so that Kiku and Hashi, by gaining superhero powers, rise against the world order, making it collapse and thus restoring chaos.

Values such as love, music, humanism do not stand a chance in the universe created by Murakami Ryū. The only means of salvation seems to be action, but definitely a destructive action at that. What Hashi tries through music, Kiku seems to manage through action.

The world of consumption does not eliminate art; quite the contrary, it identifies it with the objects of immediate pleasure and offers it the power of quick reproduction, thus stripping it of its uniqueness and power of fascination. Hashi's music could definitely be a profession of faith in favour of art and to the benefit of the supporters of its transcendence, but the way in which rock music is used for financial gains - the expression of these manipulations of meaning is Mister D. - and especially, in this context, the degradation of the concept of an artist, turned into the rock star, hungry for orgies with sex, alcohol and drugs, erases any trace of art's sacredness as its transcendent nature is pulverized into worthless fragments. The power of art is ephemeral and it does not last longer than the moment of its consumption - this seems to be the message transmitted by the author, through Hashi. Thus, in Hashi's case, music proves to be nothing more than a search for the sounds he had heard in his prenatal condition and which, during his childhood, he is under the impression that he re-hears in his sleep, at the psychiatric clinic where he had been taken together with 
his brother Kibu, so that they could be treated for autism. At the clinic, through certain sounds that reproduced heartbeats, he was given the feeling of safety and of the absence of consciousness, which he must have experienced as a fetus in his mother's womb. By singing, Hashi seeks to recover that state through music. The liberation from the body and from consciousness, through art - through rock music, in Hashi's case is illusory, nothing more than a mask that hides a more subtle form of violence - a violence that acts through pleasure and seduction. In Kiku's case, violence receives the mark of the heroic, but an upside-down heroic. His adventure is not an adventure of knowledge, but one of destruction. Kiku, as opposed to Hashi, understood, from the very beginning, that violence must be directed not at the one who survived in a hostile world, but at a world that proved to be nothing more than an even larger coin locker, a world of objects that do not remain mere objects, since they induce a certain idea of a metaphysical presence. Bill Brown notes the dual perspective on imagining objects and explains that the magical (totemic, fetishizing) value of things is given by what is excessive in objects: "You could imagine things, second, as what is excessive in objects, as what exceeds their mere materialization as objects or their mere utilization as objects-their force as a sensuous presence or as a metaphysical presence, the magic by which objects become values, fetishes, idols, and totems" (Brown 5). The need to destroy the world can thus also be translated through the two characters' desire to liquidate a society in which the objects excessively produce a false metaphysical presence (simulacrum) and simulations. In the novel, there are countless examples of objects that had been converted by the postmodern society into fetish objects or idols; in this sense, the mass-media played an immense role in the production of certain such objects, dematerialised of their own matter and reconverted into images. For instance, Hashi is attached to his rock star image, created by the mass-media, and the television becomes his mirror: "Television became his mirror" (Murakami 224). Later, however, he develops a true aversion to the objects that reflect his image: "Hashi had developed a strong aversion to anything that could reflect an image. Mirrors horrified him, as did windows at night, polished black marble, shiny chrome bumpers, or a still body of water" (Murakami 378). Another outstanding scene is that of the recording of Kiku's meeting with the mother who had abandoned him in the coin locker, a meeting that was staged and transmitted live. The feeling he experiences when he sees the woman who had given birth to him was that she was not human, but rather a chunk of metal: "She was hardly human, more like some... blob...of metal" (Murakami 270). The 
mother's image of an idol is thus destroyed by reducing it to a metal object, an object that can be annihilated by the explosion of a gunshot. The scene ends with the mother's murder. The death of the mother sends him to the youth detention centre where the thoughts of destroying the world gradually take shape. However, this episode stands out, since, for Murakami, violence has a dual valence. However, this episode also stands out from the viewpoint of the mother-son relationship, since, in Murakami's work, violence is not merely a way of shocking the reader, but also an ambiguous, dual presence. Thus, if the image of the mother is undoubtedly sacralised, then could it be that what the author attacks here is the fetishization of an image that loses its original meaning, transforming a sign into its representation? By abandoning her own child in the coin locker, the woman who had given birth to it loses, in the traditional view, the symbolic function and, implicitly, she herself transforms into her own anti-symbol.

By substituting the functioning mechanics of the world, seen as an immense coin locker, mechanics which, dividing the people into prisoners and guards, functions in only one direction - the latter making sure that nobody escapes, with a universal law of violence that would awaken all those hopelessly trapped in the coin lockers of the consumer world, Kiku begins his murderous attack on Tokyo - namely, in the city centre, represented by the Shinjuku district, with its thirteen skyscrapers, the symbol of the post-industrial society and of commodification. If the violence through music, promoted by Hashi, was unsuccessful, the one remaining chance is that of generalizing violence on the scale of the entire world, the path chosen by Kiku. His activism awards no value to the power of music, in relation with the power of destroying the society.

The expression of the stability of a world in which the unforeseen is excluded is represented by the Shinjuku district, the centre of the business world, with its thirteen skyscrapers. By translating this view, the novel's central motif becomes the search and destruction of the centre, an ironic retort to the idea of the centre-periphery relation, foreign to the traditional Japanese thought, but so deeply rooted in the modern western thought.

Without directly encroaching on the nature of the centre, the postmodern poetics proclaimed not the disappearance of the relation between the centre and the periphery - a relation in which the periphery functions within the line-of-sight of the centre -, but rather the problematization of this relation and, by assimilating the principle of relativity from scientific thought, it declared the ubiquity of the centre. In 
Murakami's view, the destruction of Tokyo's centre represents the balanced disruption in the relation of subordination between the periphery and the centre, and the proclamation of chaos in the form of a new beginning. If the centre symbolically represents consciousness, then the return to brute force, after the destruction of reason, which is the expression of the intellect, leads to the establishment of a new order - the order of a world without history, a world in which history merely just came into being atop the ruins of the old one. The return to the barbaric state from before this world, a return that is possible through the destruction inflicted by the Datura gas, could regenerate the world and could recover the meaning of history and, implicitly, the meaning of the real. The new order is one without people, without subject and without memory, replaced by an order of objects without memory which, in the absence of people, lack the metaphysical presence. The apocalyptic scenery from the end of the novel is the expression of a world of objects that remained functional, but in which no human survived. What role would the object then play, within the new order? No obvious role, seems to be Ryū Murakami's answer. Basically, the foreshadow of this ending occurs in the very beginning of the novel, which depicts the image of the abandoned coalmine on the island on which Hashi and Kiku had been raised: "The neat gray rows of miners' quarters seemed normal enough except for the occasional tuft of weeds pushing through a broken window, but there was an eerie stillness, almost as if a siren had sounded and everyone had cleared out, leaving the boys as a human sacrifice" (Murakami 26). Could it be that the image at the end, depicting an abandoned Tokyo, foreshadowed the posthuman universe?

In this sense, the adventure of the destruction through chaos and violence is translated, in the case of the two protagonists, into the desire to recover certain realities from before their birth, namely that state completely devoid of consciousness and will, a recovery that is only possible by tearing the fundamentals of the world to the ground.

\section{References:}

Baudrillard, Jean. Simulacra and Simulations, in Selected writings, edited with an introduction by Mark Poster. Stanford University Press, 1988.

Brown, Bill. “Thing Theory.” Critical Inquiry 28.1 (2001): 1-22. 
Bryson, Joanna J. "The Confabulation of Self." Memory in the Twenty-First Century. New Critical Perspectives from the Arts, Humanities, and Sciences. Ed. Sebastian Groes. Palgrave Macmillan, 2016: 334.

Frențiu, Rodica. "Haruki Murakami. Possible Questions - Possible Worlds. The Memory of An Unseen World." Orientalia Parthenopea Journal. Ed. Giovanni Borriello. no. XI, Napoli, Italy, 2011.

Hutcheon, Linda. A Poetics of Postmodernism. History, Theory, Fiction. London and New York: Routledge, 1996.

Kouno, Akihisa, Charles F. Johnson. "Child abuse and neglect in Japan: Coinoperated-locker babies." Child abuse \& Neglect 19.1 (1995): 25-31.

McHale, Brian. Constructing Postmodernism. London and New York: Routledge, 1992.

Murakami, Ryū. Coin locker babies. London: Pushkin Press, 2013. Translated by Stephen Snyder.

Snyder, Stephen. "Extreme imagination: the fiction of Murakami Ryū." Fiction of Contemporary Japan. Ōe and beyond. Ed. Stephen Snyder and Philip Gabriel. University of Hawaii Press, 1999. 